(ISAEECE 2017)

\title{
Evolution of the particle shape of sands under ring shear
}

\author{
Jianqiao $\mathrm{He}^{1,2,3}$ a, Houzhen Wei, ${ }^{1, b}$, Jianjun Wang ${ }^{2}$, Huodong Chen ${ }^{1}$
}

\author{
'State Key Laboratory of Geomechanics and Geotechnical Engineering, Institute of Rock and Soil \\ Mechanics, Chinese Academy of Sciences, Wuhan \\ ${ }^{2}$ Guangxi Road and Bridge Engineering Group Co.,Ltd, Nanning \\ 3University of Chinese Academy of Sciences, Beijing \\ aHejianqia0957@163.com, bhzwei@whrsm.ac.cn, ‘625445306@qq.com
}

\begin{abstract}
Keywords: particle shape; roundness; flatness; calcareous sand
Abstract: The particle shape is a key factor in the strength and compatibility of granular material. To investigate the evolution of the particle shape of two kind of sands. The quartz sand from Fujian and the calcareous sand from the South China Sea, were chosen for ring shear tests. The sieving method and laser grain-size analyzer were used to obtain the particle size distribution, and the microscope technique were employed to characterize the particle shape in terms of roundness and flatness. The experimental results indicate that the change of the particle size of the calcareous sand is more significant than the quartz sand. The roundness and flatness of the calcareous sand particles decreased obviously while the roundness of the quartz sand was scarcely changed and the flatness increased. It is shown that the large displacement shear makes the calcareous sand more rounded and quartz sand more roughed.
\end{abstract}

\section{Introduction}

The porous media in the soil consists of grain skeleton and pore. The pore and embedding effect were effected by particle size and shape, thereby impacting the mechanics and distortion characteristic.

Due to the importance of the particle shape, the researchers studied on the shape of non-cohesive soil. fractal theory had been employed first to obtain information on the shape of granular materials by L. E. Vallejo[1]. With image processing tool of matlab, the shape of calcareous sand was analyzed by Chen \& Wang[2]. It proposed that fractal dimension of calcareous sand was between $0.95 \sim 1.07$. A preliminary study of measurement and evaluation of two sets of limestone grain shapes were examined by Zhang[3]. It found the parameters of length-width ratio, flatness and sphericity could more sensitively reveal the differences. E. T.Bowman[4] analyzed the particle morphology was quantifiably described by use of complex Fourier analysis. It found that breakage of particles by crushing was shown to affect the morphological signature differently depending on the type of sand. With an increase in the level of abrasion, the shape fractal dimension number decreased in value and the fragmentation fractal dimension number increased in value, whereby the gravels were subjected to abrasion in a jar milling test by L.E. Vallejo[5]. Sadrekarimi[6] performed ring shear on Ottawa soil and Illinois River soil found the damage produced that were more angular and rougher than the original particles. In interparticle friction varies with particle texture (or roughness)[7]. Liu[8] investigated the relationship between particle shape and the mechanical property of sands were made up of rounded and angular particles, respectively, using direct shear apparatus. Interestingly, they showed that the critical friction angle reduces linearly with the increase in roundness and particle regularity, while the dilation angle increases with the increase in particles irregularity.

Although the study of the particle shape has been mature, but the law of the particle shape is ambiguous under large-displacement shear. Little comparative study on the law of the particle shape after shearing of different materials. In this paper, in order to reveal the law of the particle shape under large-displacement shear, a series of ring shear tests were tested for Fujian standard sand (quartz sand) and calcareous sand, using image processing techniques. 


\section{Material tested and experiment method}

Material tested. The soil tested was calcareous sand, taken from the South China Sea and quartz sand, taken from Fujian, respectively. Quantitative analysis of the composition of calcareous sand using D8 ADVANCE X-ray diffractometer, which manufactured by Bruker AXS, Germany. $\mathrm{CaCO}_{3}$ and $\mathrm{MgCO}_{3}$ content of $81.08 \%$ and $11.55 \%$ in calcareous sand respectively, however, $\mathrm{SiO}_{2}$ content of $96 \%$ in quartz sand. The results indicate that mineral composition of calcareous sand are aragonite, dolomite and calcite.

Experiment equipment and method. This paper studied the evolution of shape properties under the large-displacement shear. The triaxial device is the limited available shear displacement. The magnitude of shear displacement that can be imposed on a specimen is also limited by the direct simple shear device. In this paper we tested on DTA-138 geotechnical ring shear, which manufactured by Japan. The ability to shear a sample uninterrupted to virtually unlimited displacement in this ring shear. This sand is tested single sized of $0.5-1 \mathrm{~mm}$. Calcareous sand and quartz sand has a maximum ( $\mathrm{e}_{\max }$ ) void ratios of 1.71 and 0.88 , respectively.We were tested the maximum void ratios. In this study was prepared by air pluviation as it is a commonly used and reliable method to achieve fairly uniform density[9]. Then all tests are performed on saturated specimens. Consolidation pressure is set to $400 \mathrm{kPa}$. After consolidation, we were sheared to $10 \mathrm{~m}$ each specimen at a rate of $4.36 \mathrm{~cm} / \mathrm{min}$ under drained conditions. Considering the content of fines after tests, the particle size distributions are got by the sieving method and laser grain-size analyzer. The shape parameter before and after tests were got by the microscope, and then the characteristics of the particle shape were analyzed.

The particle breakage parameter. The change of the particle size distribution reflected the particle breakage intuitively. The amount of particle breakage is quantified by means of Hardin's[10] relative breakage, $\mathrm{B}_{\mathrm{r}}$, which is defined as (Eq.1)

$$
B r=B_{t} / B_{p 0}
$$

Where $B_{p 0}$ is the pre-shearing potential for breakage that is area of ABCD (Fig.1), $B_{t}$ is the amount of total breakage that is area of ABCE. Hardin ignored damage to silt particle. However, in this study, breakage will take into account in the particle greater than $0.01 \mathrm{~mm}$.

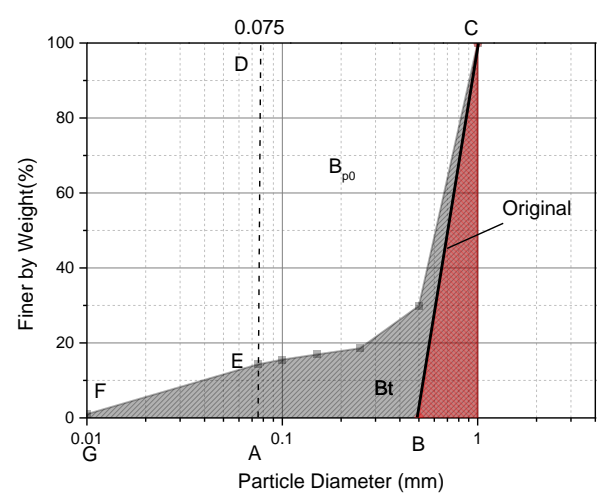

Fig. 1 Illustration for the definition of $\mathrm{Br}$

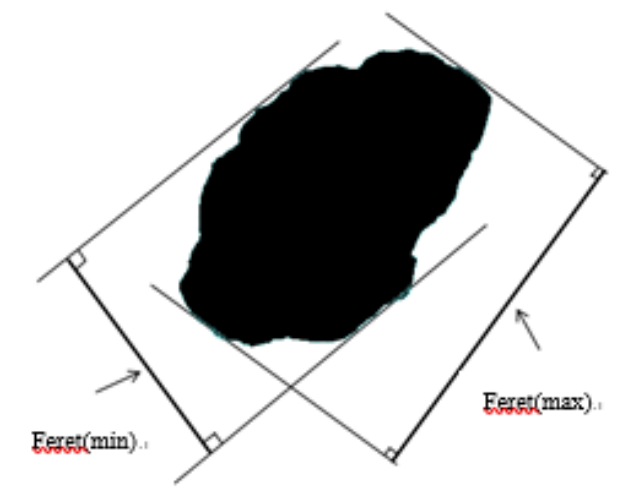

Fig. 2 Illustration for the particle shape parameters 
The particle shape parameters. Firstly, the two-dimensional projected images of particle are got by the microscope. Then change the gray image into binary image, thereby got its the geometric parameters, such as maximum and minimum feret's diameter, area and so on. Finally, the particle shape parameter before and after tests are calculated. This paper attempts to describe the particle shape in two level. On one hand, flatness[11], which depicts the particle's outline. Flatness is defined as (Eq.2)

$$
e=\text { Feret }(\max ) / \text { Feret }(\min )
$$

Where Feret (max) and Feret ( $\min$ ) are maximum and minimum feret's diameter, respectively (Fig.2). On another hand, roundness[12], which depicts the rough on surface proposed by Liu. Roundness is defined as (Eq.3)

$$
\text { Roundness }=P^{2} /(4 \pi A)
$$

Where $\mathrm{P}$ and $\mathrm{A}$ are projected girth and projected area, respectively.

\section{Test results and discussion}

The evolution of particle breakage. Particle breakage induced the evolution of grain size distributions in the Shear Band was sheared to $10 \mathrm{~m}$ (Fig.3). The particle-size distribution curve of quartz sand more steeper than the particle-size distribution curve of calcareous sand after tests. The average particle size $\left(\mathrm{d}_{50}\right)$ of calcareous sand was reduced from $0.5 \mathrm{~mm}$ to $0.349 \mathrm{~mm}$, and quartz sand was reduced from $0.5 \mathrm{~mm}$ to $0.475 \mathrm{~mm}$ (Table 1). The fines of calcareous sand more than that of quartz sand obviously. It indicate that the change of particle size of calcareous sand larger than that of quartz sand. The amount of crushing also reflects the particle size changes directly. In order to analyze the change of particle size further, quantitative analysis of particle crushing. Calcareous sand was damaged more severely $\left(\mathrm{B}_{\mathrm{r}}=0.482\right)$ than quartz sand $\left(\mathrm{B}_{\mathrm{r}}=0.166\right)$ that was sheared to $10 \mathrm{~m}$ (Table 1). The results show that the quantity of particle breakage on calcareous sand is much more than that on quartz sand, further the change of particle size of calcareous sand larger than that of quartz sand.

Table 1 The parameters of particles

\begin{tabular}{cccc}
\hline Material & $\mathrm{d}_{50}$ (before test) $/ \mathrm{mm}$ & $\begin{array}{c}\mathrm{d}_{50}\left(\begin{array}{c}\text { (after test) } \\
/ \mathrm{mm}\end{array}\right. \\
\mathrm{Br}\end{array}$ \\
\hline calcareous sand & 0.50 & 0.349 & 0.482 \\
quartz sand & 0.50 & 0.475 & 0.166 \\
\hline
\end{tabular}

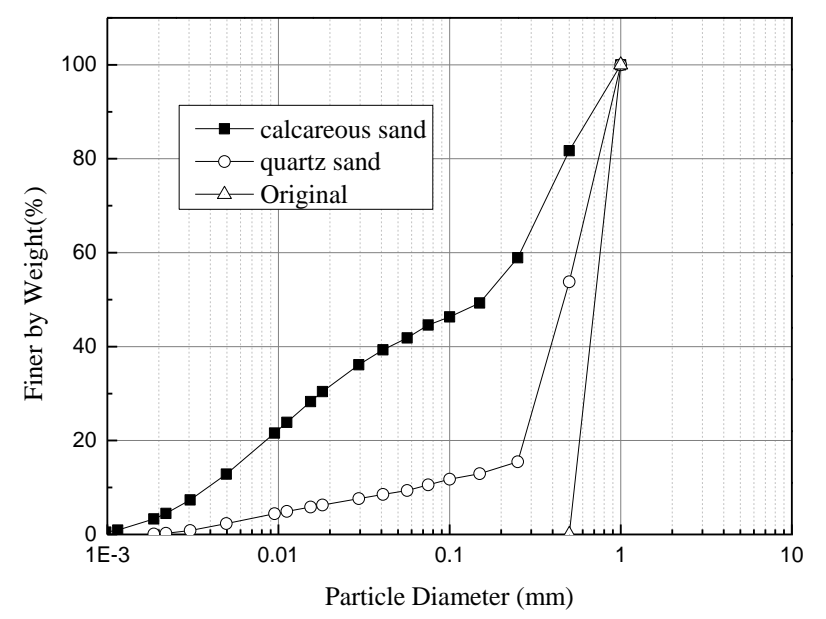

Fig. 3 the particle size distribution before and after tests 


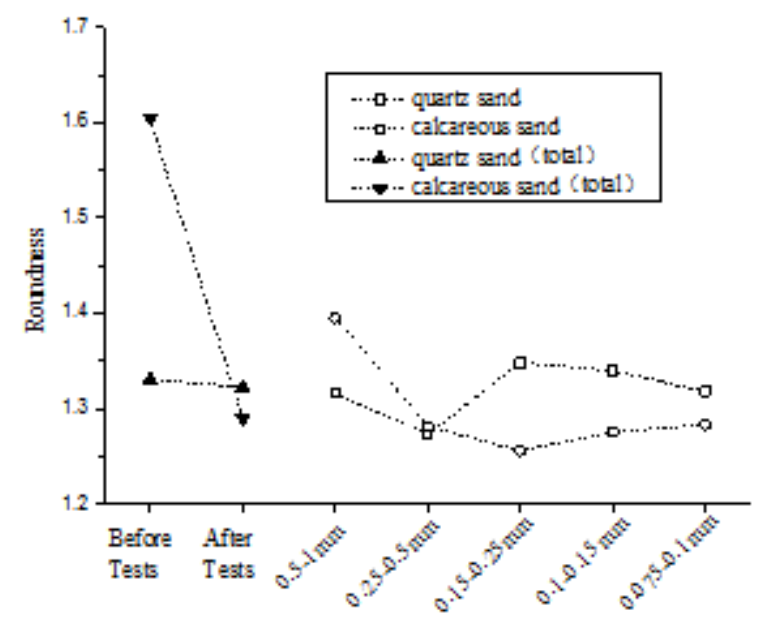

Fig. 4 The change of roundness before and after tests

The change of particle shape. According to statistics the particle shape before and after tests, it suggested that roundness of calcareous sand larger than that of quartz sand before tests (Fig.4). The roundness of calcareous sand and quartz sand decreased that was sheared to $10 \mathrm{~m}$. However, the roundness of the quartz sand was little decreased. It indicated that performed large-displacement shear the calcareous sand was more rounded, and quartz sand was more rougher than the original particles. It was found that the roundness of the particle size of $0.15-0.25 \mathrm{~mm}$ was the smallest, and the largest of the roundness of the quartz sand was particle size of 0.15 to $0.25 \mathrm{~mm}$. During shearing, the prolate of irregular particles were subjected to particle breakage, that caused by stress concentration, and produced particle more rounded. This could be a result of intense rolling and abrading on the calcareous sand of the particle size of $0.15-0.25 \mathrm{~mm}$ and mild rolling and abrading on the quartz sand of the particle size of $0.15-0.25 \mathrm{~mm}$.

Table 2 The change of the roundness before and after tests

\begin{tabular}{ccccccc}
\hline Material & Mean & $\begin{array}{c}\text { Before tests } \\
\text { CI of Mean }\end{array}$ & SD & Mean & $\begin{array}{c}\text { After tests } \\
\text { CI Mean }\end{array}$ & SD \\
\hline $\begin{array}{c}\text { calcareous } \\
\text { sand }\end{array}$ & 1.605 & $\begin{array}{c}1.517-1.69 \\
3\end{array}$ & 0.304 & 1.289 & $1.275-1.303$ & 0.146 \\
quartz sand & 1.331 & $\begin{array}{c}1.300-1.36 \\
2\end{array}$ & 0.155 & 1.323 & $1.293-1.353$ & 0.330
\end{tabular}

Note: The CI of Mean is lower 95\% CI of mean and upper 95\% CI of mean, SD is standard deviation of sample.

Table 3 The change of the flatness before and after tests

\begin{tabular}{ccccccc}
\hline Material & Mean & $\begin{array}{c}\text { Before tests } \\
\text { CI of Mean }\end{array}$ & SD & Mean & CI of Mean & SD \\
\hline $\begin{array}{c}\text { calcareous } \\
\text { sand }\end{array}$ & 1.560 & $\begin{array}{c}1.437-1.68 \\
\text { Cantests }\end{array}$ & 0.374 & 1.410 & $1.383-1.437$ & 0.275 \\
quartz sand & 1.388 & $\begin{array}{c}1.349-1.42 \\
7\end{array}$ & 0.198 & 1.401 & $1.375-1.427$ & 0.282
\end{tabular}

Note: The CI of Mean is lower 95\% CI of mean and upper 95\% CI of mean, SD is standard deviation of sample. 


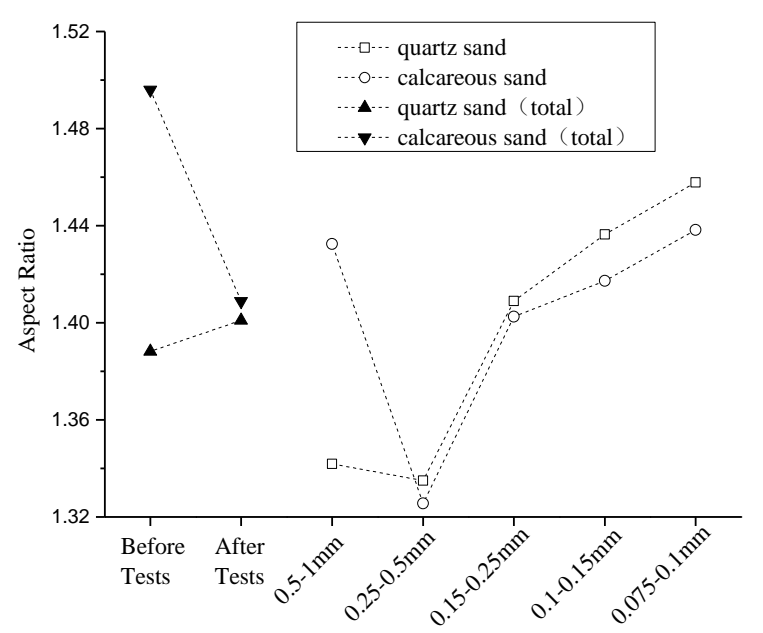

Fig. 5 The change of flatness before and after tests

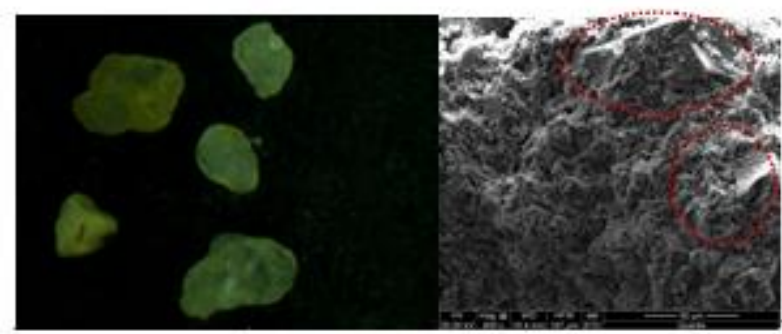

Fig. 6 The image of quartz sand before and after tests

According to the statistical method to get the flatness both before and after test (Table 3). A significant difference in the flatness of the two specimens (calcareous sand and quartz sand) were shown in Fig.5. The flatness of calcareous sand reduces (more rounded or square) obviously (from 1.496 to 1.409). Conversely, the flatness of calcareous sand increases (more flat). To better visualize the particle after shearing, the sheared sand was observed on scanning electron microscope (SEM). The SEM photos illustrates that the quartz sand had more roughed and flatness is shown in Fig.6.

The flatness of the quartz sand with particle size of $0.25-0.5 \mathrm{~mm}$ was the smallest. While the flatness of the $<0.25 \mathrm{~mm}$ particles was larger than the original. During large-displacement shearing, grain skeleton consist of coarse particles that primarily subjected to shear loading(Fig.7 \& Fig.8). So the roundness and flatness of coarse particles decreased, that caused by rolling and abrading. The damaged fines $(<0.25 \mathrm{~mm})$ fall into the skeleton pores, not the part of the skeleton, the fines in the pores had not been rolling and abrading (Fig.8). Therefore the flatness of the fines larger than original. Due to calcareous sand particle is prone to crush under stress, with increasing shear displacement, the skeleton could not withstand the external load and failure. Particle crushing produced the pore compression, and a part of broken particle become the skeleton again. Circularly, the particles unremitting rolling and abrading, and the particle trended to regular continuously.

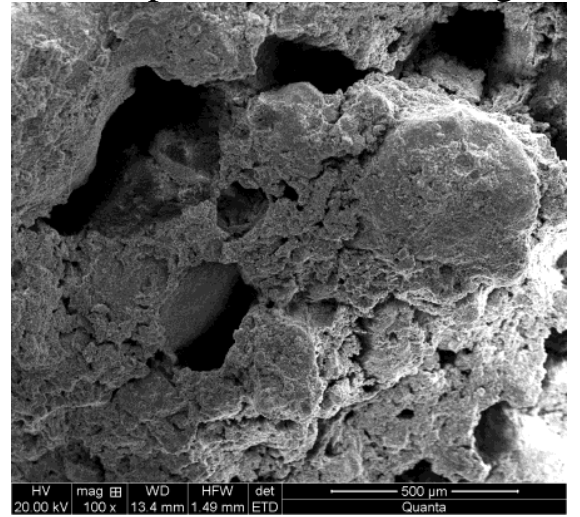

Fig. 7 The SEM image of shear band 


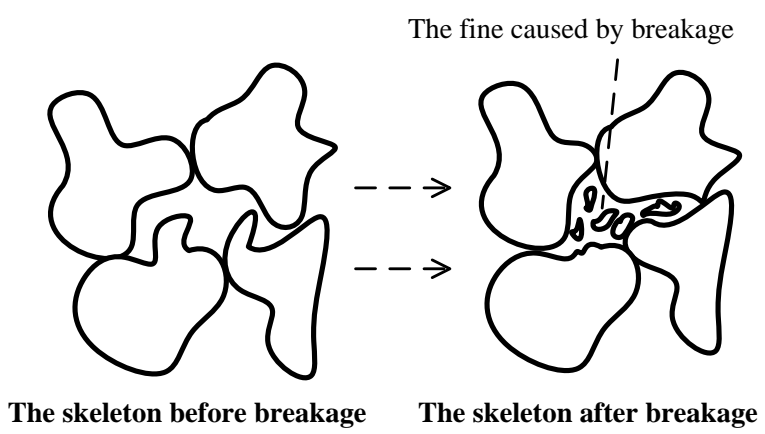

Fig. 8 Illustration for the skeleton before and after breakage

After large-displacement shear, the flatness of calcareous sand and quartz sand had the same trend in each size. By using SEM, obtaining a particle distribution on the shear band used to making a simple model about breakage process (Fig. 8), the external load of the grain skeleton broken and the fines fallen into the pore preventing from breakage; after the original grain skeleton (the previous process) was failure, the new skeleton composed of part of original grain skeleton and part of particle in pore, the flatness kept decreasing along with increasing shear displacement. Therefore, the particle shape change was related to the severeness of breakage.

\section{Conclusions}

In this study, we performed a series of ring shear tests on calcareous sand and quartz sand. Particle damage and shape change could be observed in the shear band of the tests. The following conclusions can be drawn based on the finding of this study:

(1) The calcareous sand was damaged more severely $\left(\mathrm{B}_{\mathrm{r}}=0.482\right)$ than quartz sand $\left(\mathrm{B}_{\mathrm{r}}=0.166\right)$ in large-displacement shearing, and the particle size of the calcareous sand changed more than the quartz sand;

(2) After large-displacement shear, the shape of calcareous sand tends to be more regular, in contrast, quartz sand tends to be more irregular;

(3) After large-displacement shear, the flatness of calcareous sand and quartz sand have the same trend for full particle size range.

\section{Acknowledgements}

This work was financially supported by the Strategic Priority Research Program of the Chinese Academy of Sciences, Grant No. XDA XDA13010200, Youth Innovation Promotion Association of CAS under Grant No.2015272.

\section{References}

[1] L. E. Vallejo. Fractal analysis of granular materials. Geotechnique 1995, 1: 159-163.

[2] Chen Hai-yang, Wang Ren, Li Jian-guo, Zhang Jia-ming. Grain shape analysis of calcareous soil. Rock and Soil Mechanics, 2005, 26(9): 1389-1392 (In Chinese).

[3] Zhang Jia-fa, Ye Jia-bing, Chen Jin-song, Li Shao-long. A preliminary study of measurement and evaluation of breakstone grain shape. Rock and Soil Mechanics, 2016, 37(2): 343-349 (In Chinese).

[4] Bowman E T, Soga K, Drummnond W. Particle shape characterization using Fourier descriptor of analysis. Geotechnique, 2001, 51(6): 545-554.

[5] L. E. Vallejo, Z. Chik, M. Measurement of the Abrasion of Granular Materials Using Fractals. Geoflorida, 2010, 560-569. 
[6] Sadrekarimi, A, Olson, S M. Particle damage observed in ring shear tests on sands. Canadian Geotechnical Journal, 2010, 47: 497-515.

[7] Peijun Guo, Xubin Su. Shear strength, interparticle locking, and dilatancy of granular materials. Canadian Geotechnical Journal, 2007, 44: 579-591.

[8] Liu Qing-bing, Xiang Wei, Lehane B M, et al. Experimental study of effect of particle shapes on shear strength of sand and tip resistance of driven piles. Chinese Journal of Rock Mechanics and Engineering, 2011, 30(2): 400-410 (In Chinese).

[9] Lade, P A, Liggio, C D, and Yamamuro, J. A Effect of non-plastic fines on minimum and maximum void ratios of sand. Geotechnical Testing Journal, 1998, 21(4): 336-347.

[10] Hardin B O. Crushing of soil particles. Journal of Geotechnical Engineering ASCE, 1985, 111(10): 1177-1192.

[11] L H Mark,W P Neil . Selection of descriptors for particle shape characterization. Particle and Particle System Characterization, 2003, 20(1): 25-38.

[12] Liu, S, and Matsuoka, H. Microscopic interpretation on a stress-dilatancy relationship of granular materials. Soils and Foundations, 2003, 43(3): 73-84. 